http://dergipark.gov.tr/ataunizfd

\title{
Erzurum İli Beypınarı Mahallesi Arazi Toplulaştırma Projesinin Yol Ağı Yeterliliği Açısından Değerlendirilmesi
}

\author{
Yasemin KUŞLU* (iD) Emre ERTEM \\ Atatürk Üniversitesi, Ziraat Fakültesi, Tarımsal Yapılar ve Sulama Bölümü, Erzurum, Türkiye \\ (*Sorumlu yazar e-mail: ykuslu@atauni.edu.tr) \\ DOI: 10.17097/ataunizfd.541809
}

Geliş Tarihi (Received Date): 19.03.2019

Kabul Tarihi (Accepted Date): 04.09.2019

\begin{abstract}
ÖZ: Bu çalışma arazi toplulaştırma projelerinin yol ağı oluşturulmasında etkinliğini değerlendirmek için yapılmıştır. Araştırma alanı olarak Erzurum-Beypınarı Mahallesi seçilmiștir. Calıșmada ișletmeler toplulaștırma öncesi sahip olduğu parsel sayısı 1-10, 11-15, 16-20 ve 20+ olacak şekilde gruplandırılmış ve şansa bağli olarak yoğunluğuna göre her bir gruptan işletme seçilmiştir. Toplulaştırma öncesi ve sonrası işletmelere ait parsellerin yol ağı durumu değerlendirilmiş̧tir. Yol ağı, alan-yol uzunluğu uygunluğu (AYU) ve kuș uçuşu alan-yol uzunluğu uygunluğu (KUYUU) göstergelerine göre değerlendirilmiștir. Araştırmada, arazi toplulaştırma projesi ile işletme merkezi ile parseller arası yol uzunluğu ortalamasının \%7.14 dolayında azaldığı tespit edilmiştir. Arazi toplulaştırma sonrası Beypınarı yerleşkesi ile parseller arasındaki yolların işletim sisteminin iyileștiği görülmüștür. Toplulaş̧ırma öncesi ve sonrasında yol uzunluğu (YU) ile kuş uçuşu yol uzunluğu (KUYU) arasındaki farktaki azalma yol işletim sistemindeki iyileşmenin göstergesi olup proje ile $\% 62.50$ gibi büyük bir oranda gelişme kaydedilmiştir. En fazla gelişme, toplulaştırma öncesi fazla sayıda parsele sahip işletmelerde gerçekleşmiştir. Bu durum özellikle yakıt tüketimini azaltması ve yolda geçirilen zamanın azaltılması açısından önemli olduğu bir gerçektir. Arazi toplulaştırma projelerinin kırsal alandaki yol altyapısının gelişmesinde kullanılabilecek en etkili uygulama olduğu sonucuna varılmıştır.
\end{abstract}

Anahtar kelimeler: Arazi toplulaştırması, Tarla içi yol ağı, Kırsal altyapı, Beypınarı, Erzurum

Evaluation of The Land Consolidation Project of the Beypınarı District of Erzurum Province in Terms of Road Network Adequacy

\begin{abstract}
This study was conducted to evaluate the effectiveness of land consolidation projects in the road network. ErzurumBeypinarı rural settlement was chosen as the research area. In this study, the number of parcels owned by the farms before the land consolidation were grouped as 1-10,11-15, 16-20 and 20+. The farms were selected from each group according to the density by random sampling method. Before and after land consolidation, road network sufficiency of the parcels with the farms was evaluated. The road network was evaluated according to the compactness of the farm (AYU) and external farm compactness (KUYUU) coefficients. In the research, it was determined that the average length of the road between the farm center and parcels decreased by 7.14\% with the land consolidation project. After the land consolidation, it was seen that the operating system at the road network between Beypinarı and parcels improved. The decrease in the difference between road length (YU) and air line path length (KUYU) before and after consolidation is an indicator of the improvement in the road network system, and the project has achieved a great improvement by $62.50 \%$. The most development appeared in farms with a large number of parcels before consolidation. This is especially important in terms of reducing fuel consumption and reducing the time spent on the road. It was concluded that land consolidation projects are the most effective way to develop the road infrastructure in rural areas.
\end{abstract}

Key words: Land consolidation, Field road network, Rural infrastructure, Beypınarı, Erzurum

\section{GíRiş}

Tarım işletmelerinin tarla tarımından yeterli gelir elde edememelerinin nedenlerinden bazıları; bozuk şekilli, küçük ve coğrafik konumları birbirinden farklı parsellerde üretim yapmalarıdır. Parsel alanlarının küçülmesinin ülkeden ülkeye değişiklik gösteren yasal ve teknik eksiklikleri bulunmaktadır. Miras ve alım-satımlar nedeniyle parçalanmanın yanı sıra sulama, drenaj ve yol gibi altyap1 hizmetlerinin götürülmesi ile de parçalanma söz konusu olmaktadır.

Fiziksel anlamda arazi toplulaştırması; kırsal mekânda aynı işletmeye ait, birbirinden ayrı coğrafik konumda, işletme merkezine gör farklı yönlerde, tarımsal işletme bakımından uygun olmayan şekil ve boyuttaki parsellerin, sulama, drenaj, yol gibi ağlara bağlantılı ve ekolojik gereklere uygun biçimde bir araya getirilerek yeniden düzenlenmesi olarak tanımlanabilir. Arazi toplulaştırma ile parseller yeniden düzenlenerek olumlu yönde bir parsel dönüşümü sağlanmış olmaktadır. Bu durum tarım işletmelerinin yönetimini kolaylaştırmakla beraber kırsal kalkınma süreçlerini doğrudan etkilemektedir. $\mathrm{Bu}$ konuda yapılmış çok sayıda araştırma bulunmaktadır (Uçar ve Kara, 1997; Uçar vd., 2003; Uçar ve Kara, 2006; Kumbasaroğlu ve Dağdemir, 2007; Boyraz ve Üstündağ, 2008; Kuşlu ve Yağanoğlu, 2007; Çelebi, 2010; Çakmak ve Eminoğlu, 2013; Sönmezyıldız ve Çakmak, 2013; Boztoprak vd., 2015; Basar, 2016; Peker ve Dağdelen, 
2016; Dağdelen vd., 2017; Akkaya vd., 2017; Tezcan, 2018). Sıralanan araştırmaların ortak konuları; arazi toplulaştırma çalışmaları ile birim alandan daha fazla verimin alınması, modern üretim tekniklerinin kullanımına olanak verilmesi, kamu yatırımlarının daha ucuza gerçekleştirilmesi ve bu hizmetlerden faydalanan kişiler arasındaki sosyal huzur varlığının inşa edilmesi ile ilgilidir. Diğer bir deyişle tarım arazilerinin etkin ve sürdürülebilir kullanımında arazi toplulaştırması başat rol oynamaktadır.

Arazi toplulaştırma çalışmalarının farklı bir etkisi de kırsal alanda fiziksel altyapı üzerine olup bu konu ile ilgili olarak Kirmikil ve Aydus, (2018); Akdeniz ve Temizel, (2018); Kuzu vd., (2018); Polat ve Manavbaşı, (2012); Peker ve Dağdelen, (2016) ve Değirmenci ve ark., (2017) tarafindan yapılan araştırmalar; kırsal alan altyapısında önemli rol oynayan yolların analizini konu edinmektedir.

Uygulaması tamamlanmış bir arazi toplulaştırma projesinin başarısını gösteren bir takım ölçütler vardır. Toplulaştırma oranı, ortalama parsel büyüklüğü, işletme başına ortalama parsel sayısı, sulama, drenaj ve yol ağından yararlanma yeterliliği, işletme başına düşen arazi varlığındaki değişim, parsel şekillerinde gözlenen düzelmeler bu ölçütlerden bazılarıdır (Kuşlu, 2004; Akkaya Aslan et al., 2007; Arıcı ve Akkaya Aslan, 2014; Boztoprak ve ark., 2015). Arazi toplulaştırma çalışmalarının son yıllardaki değerlendirme ölçütlerine bakıldığında, yol yeterlilikleri ile ilgili farklı indekslerin de ele alındığ 1 görülmektedir. Alan Yol uzunluğu uygunluğu göstergesi de bu ölçütlerden birisi olup, arazi toplulaştırmasının fiziksel etkinliğinin belirlenmesinde kullanılmaktadır (Değirmenci ve ark., 2017; Akdeniz ve Temizel, 2018; Akkaya Aslan, 2018; Kuzu vd., 2018).

Türkiye'deki arazi toplulaştırma çalışmalarının yaklaşık 60 yıllık bir geçmişi olmasına karşıllık Erzurum'da bu projeler oldukça yenidir. Bu çalışmalardan birisi de Beypınarı projesidir. $\mathrm{Bu}$ araştırmada Beypınarı kırsal yerleşiminde tamamlanan toplulaştırma çalışmaları ile elde edinilen kazanımlardan; yol yeterliliğindeki değişim irdelenmiştir.

\section{MATERYAL VE METOT}

Erzurum'da ilk olarak 2004 y1lında 7103 Sayılı Bakanlar Kurulu Kararı ile Erzurum Ovası'nda Kuzgun Barajı sulama alanına giren 13 köy yerleşiminde zorunlu toplulaştırma kararı alınmıştır. Erzurum İli Ilıca İlçesinde yer alan Beypınarı Köyü de bu kapsamdaki yerleşimlerden biri olup, 2004 yilında çıkarılan 5216 Sayılı Büyükşehir Belediyesi Yasası ile
Erzurum İli Aziziye Merkez İlçeye bağlı bir mahalle niteliğine bürünmüştür. Toplulaştırma projesi 2010 yılında başlatılmış ve 2012 yılı sonunda tamamlanabilmiştir.

Beypınarı, $39^{\circ} 99^{\prime}$ kuzey enlemi ve $41^{\circ} 15^{\prime}$ doğu boylamları arasında, Aziziye İlçesine $9.5 \mathrm{~km}$, Erzurum kent merkezine $16.1 \mathrm{~km}$ mesafede yer almaktadır. TÜIKK verilerine göre nüfusu 426 olan Beypınarı'nın rakımı $1770 \mathrm{~m}$ ve toplam yüzölçümü $16.416 \mathrm{~km}^{2}$ 'dir. Toprak özellikleri açısından bakıldığında derinliği 90 $\mathrm{cm}$ alüviyal ve ince bünyeli topraklardan oluşmuş I., II. ve III. sınıf tarım arazilerine sahip olduğu görülmektedir. Ortalama arazi eğimi \%0-2 arasında değişmekte olup düz ve düze yakın bir topoğrafyaya sahiptir (Kuslu et al., 2017). Çalışma alanında bazı meteorolojik verilerin uzun yıllar (1929-2018) ortalama değerleri; sıcaklık $5.7^{\circ} \mathrm{C}$, en düşük sıcaklık $0.5^{\circ} \mathrm{C}$, en yüksek sıcaklık $11.8^{\circ} \mathrm{C}$ ve yağış $431.2 \mathrm{~mm}$ şeklindedir (MGM, 2019). Araştırma alanına ait toplulaştırma öncesi ve sonrası parselasyon durumu Şekil 1 ve Şekil 2'de verilmiştir. Araştırmanın yürütüleceği en az işletme sayısı belirlenirken, araştırmaya konu olan popülasyon sonlu ve varyans sinırlı olduğundan basit şansa bağlı örnekleme yöntemi için, sonlu popülasyonlara göre geliştirilmiş aşağıdaki eşitlik kullanılmıştır (Çiçek ve Erkan, 1996):

$$
\mathrm{n}=\frac{\mathrm{n}^{*} \sigma^{2}}{(\mathrm{~N}-1)^{*} \mathrm{D}^{2}+\sigma^{2}}
$$

Eşitlikte, n; örnek birim sayısı, N; popülasyon birim sayısı, $\sigma 2$; popülasyon varyansı, $D$; olası hata değeridir. Hesaplamalar sonucunda 12 işletme bulunmuştur. Güvenlik payı dikkate alınarak araştırmada değerlendirmede 15 işletme dikkate alınmıştır. İşletmeler sahip oldukları parsel sayılarına göre $1-10,11-15,16-20$ ve $20+$ şeklinde gruplara ayrılmış ve yoğunluklarına göre oranlanarak her gruba giren işletme sayısı belirlenmiştir. Her gruptaki işletmelerin seçiminde tesadüfi sayılar yöntemi kullanılmıştır. Arazi toplulaştırma projelerinde kullanılan en eski etkinlik ölçütü olan toplulaştırma oranı (TO), eski ve yeni parsel sayısı kullanılarak hesaplanmaktadır:

$$
\mathrm{TO}=\frac{(\mathrm{EPS}-\mathrm{YPS})}{\mathrm{EPS}} \times 100
$$

Eşitlikte, EPS; toplulaştırma öncesi parsel sayısı (adet), YPS; toplulaştırma sonrası parsel sayısı (adet) olup, göstergenin yüksek olması toplulaştırmasının daha etkili olduğunu göstermektedir. 


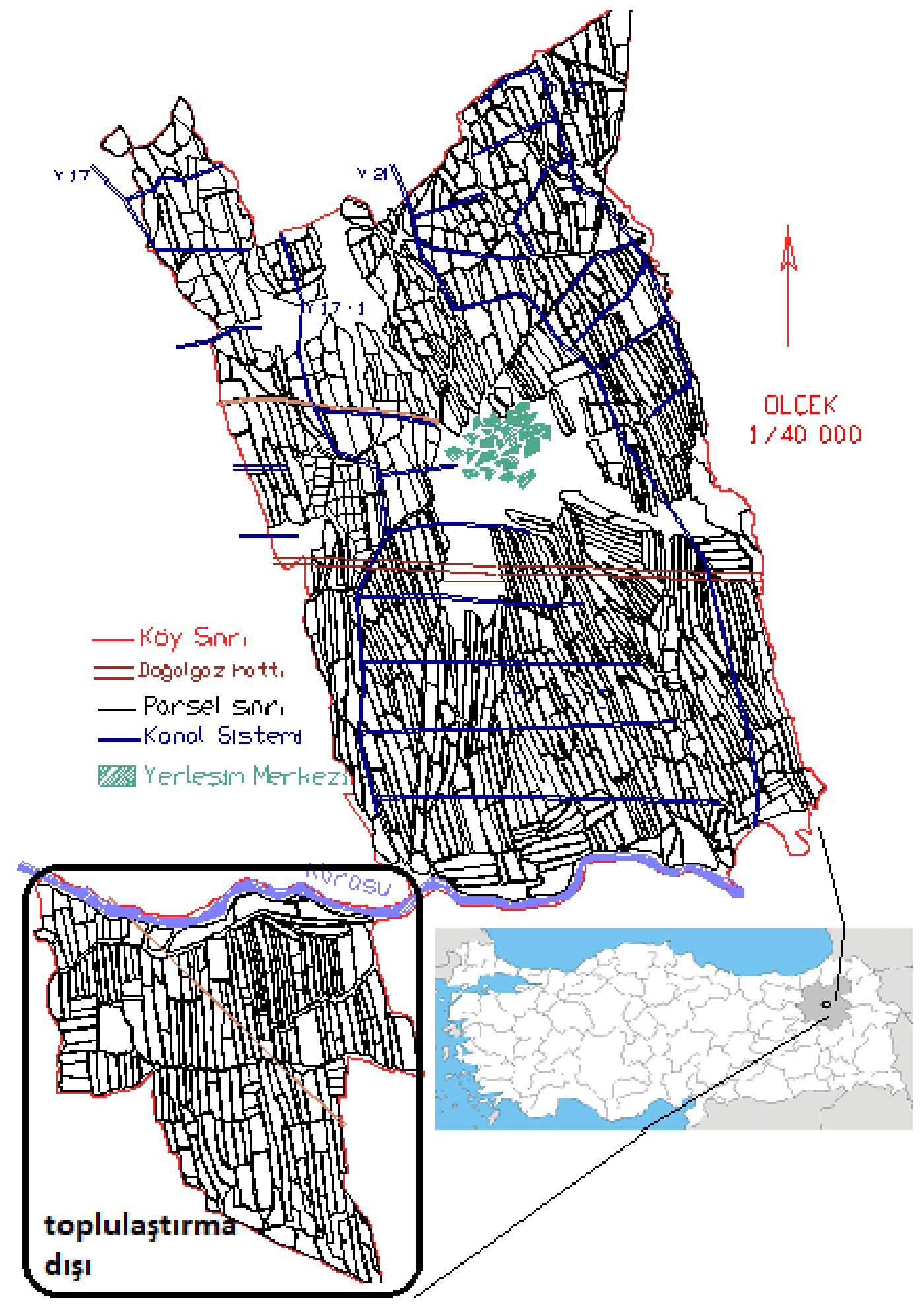

Şekil 1. Beypınarı Mahallesi’nin arazi toplulaştırma öncesi parselasyon durumu (Kuşlu, 2004) 


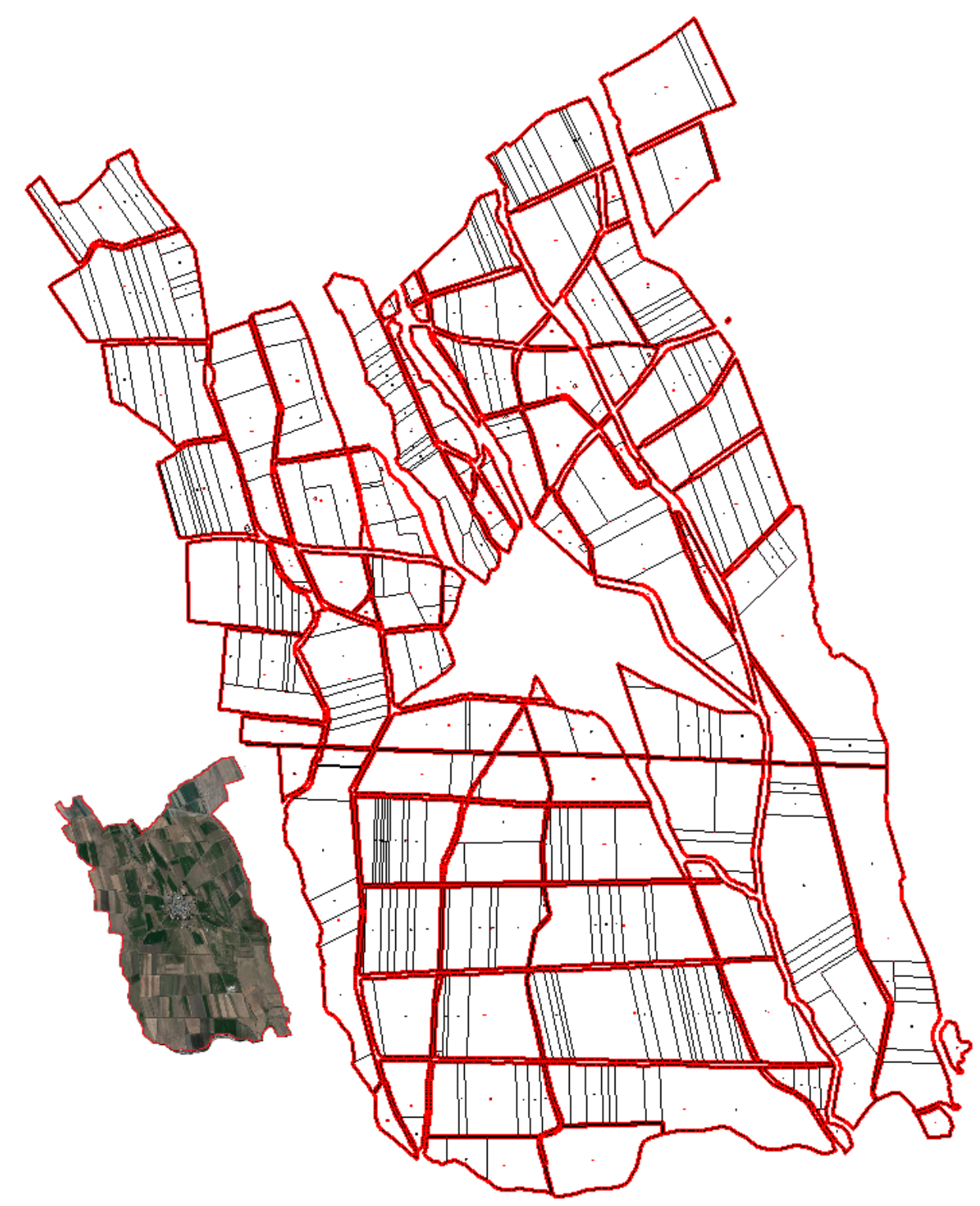

Şekil 2. Beypınarı Mahallesi'nin arazi toplulaştırma sonrası parselasyon durumu

Alan-yol uzunluğu uygunluğu (AYU) ve Alan kuş uçuşu yol uzunluğu uygunluğu (KUYUU) ölçütleri Platonova et al. (2011) ve Mc Garigal and Marks, (1995) tarafindan öne sürülmüş kavramlar olup, parsel ile işletme merkezi arasındaki yol uzunluğu veya kuş uçuşu yol uzunluğu ile parsel alanı verileri kullanılarak hesaplanmaktadır. Her iki ölçütte de parsellerdeki hissenin bir olduğu varsayılmıştır. Araştırmada yol ağı yeterliliği incelendiğinden, toplulaştırma öncesi ve sonrasında parsel hisseleri dikkate alınmamıştır.

$$
A Y U=\frac{Y U}{0.043 \sqrt{P A}}
$$

Eşitlikte, YU; yol uzunluğu $(\mathrm{km})$, PA; parsel alanı (ha) değeridir.

$$
K U Y U U=\frac{K U Y U}{0.038 \sqrt{P A}}
$$


Eşitlikte, KUYU; kuş uçuşu yol uzunluğu (km), PA; parsel alanı (ha) değeridir. Göstergelerin bire yakın olması, işletme ile parsel arasında uygun bir yol işletim sistemi olduğunu ifade etmektedir.

\section{BULGULAR VE TARTIŞMA}

Araştırmada incelenen 15 adet işletmeye ait toplam ve sabit tesislere katılım payı çıkarıldıktan sonraki net parsel alanı sırasıyla toplulaştırma öncesi 615.13 da ve 613.5 da'dır. Arazi toplulaştırma çalışmasından sonra toplam net parsel alanı 584.45 da olmuştur. Çalışmada belirlenen toplulaştırma oranının (TO) işletmelere göre dağılımı Çizelge 1 'de verilmiştir.

Çizelge 1. Beypınarı tarım işletmelerinde toplulaştırma oranları

\begin{tabular}{lllllllllllllllll} 
İşletme No & $\mathbf{1}$ & $\mathbf{2}$ & $\mathbf{3}$ & $\mathbf{4}$ & $\mathbf{5}$ & $\mathbf{6}$ & $\mathbf{7}$ & $\mathbf{8}$ & $\mathbf{9}$ & $\mathbf{1 0}$ & $\mathbf{1 1}$ & $\mathbf{1 2}$ & $\mathbf{1 3}$ & $\mathbf{1 4}$ & $\mathbf{1 5}$ & Toplam \\
\hline EPS (adet) & 10 & 13 & 63 & 14 & 24 & 16 & 19 & 14 & 8 & 7 & 20 & 7 & 16 & 61 & 7 & $\mathbf{2 9 9}$ \\
YPS (adet) & 2 & 1 & 6 & 2 & 1 & 5 & 1 & 3 & 1 & 1 & 2 & 1 & 1 & 1 & 1 & $\mathbf{2 9}$ \\
TO $(\boldsymbol{\%})$ & 80.0 & 92.3 & 90.5 & 85.7 & 95.8 & 68.8 & 94.7 & 78.6 & 87.5 & 85.7 & 90.0 & 85.7 & 93.8 & 98.4 & 85.7 & $\mathbf{9 0 . 3}$ \\
\hline
\end{tabular}

EPS; Toplulaştırma öncesi parsel sayısı, YPS; Toplulaştırma sonrası parsel sayısı

Çizelge 1'den de görüldüğü gibi arazi toplulaştırma öncesi seçilen işletmelerin beşi 1-10 parça, üçü 11-15 parça, dördü 16-20 parça, üçü de 20+ parsel grubunda tarım yaparken, toplulaştırma sonrası işletmelerin tamamı 1-10 parsel grubunda tarım yapma şansına kavuşmuştur. Bunlardan dokuz işletmenin sahibi olduğu parsel sayısı bire düşmüştür. Toplulaştırma oranı en düşük \% 68.8 ile 6 numaralı işletmede, en yüksek ise \% 98.4 ile 14 numaralı işletmede gerçekleşmiştir. Ortalama toplulaştırma oranı ise \% 90.3 olarak gerçekleşmiştir.

Arazi toplulaştırma projesinden önce ve sonra işletmelerin sahip olduğu parsellere gidebilmesi için kat etmesi gereken ortalama yol ve kuş uçuşu yol uzunlukları Çizelge 2'de verilmiştir.

Çizelge 2. Beypınarı toplulaştırması öncesi ve sonrasında ortalama yol ve kuş uçuşu yol uzunlukları ile değişim oranlar1

\begin{tabular}{|c|c|c|c|c|c|c|c|c|c|}
\hline \multirow{2}{*}{$\begin{array}{c}\text { İşletme } \\
\text { No }\end{array}$} & \multicolumn{3}{|c|}{ Toplulaştırma Öncesi } & \multicolumn{5}{|c|}{ Toplulaştırma Sonrası } & \multirow{2}{*}{$\begin{array}{c}\text { FDO } \\
(\%)\end{array}$} \\
\hline & $\begin{array}{c}\text { PS } \\
\text { (adet) }\end{array}$ & $\begin{array}{c}\text { YU } \\
(\mathbf{k m})\end{array}$ & $\begin{array}{c}\text { KUYU } \\
\text { (km) }\end{array}$ & $\mathbf{F}(\mathbf{k m})$ & $\begin{array}{c}\text { PS } \\
\text { (adet) }\end{array}$ & $\begin{array}{c}\text { YU } \\
(\mathbf{k m})\end{array}$ & $\begin{array}{c}\text { KUYU } \\
\text { (km) }\end{array}$ & $\mathbf{F}(\mathbf{k m})$ & \\
\hline 1 & 10 & 2.25 & 1.95 & 0.30 & 2 & 1.32 & 1.29 & 0.03 & 90.00 \\
\hline 2 & 13 & 1.58 & 1.34 & 0.24 & 1 & 2.20 & 2.31 & 0.11 & 54.17 \\
\hline 3 & 63 & 1.68 & 1.50 & 0.18 & 6 & 1.28 & 1.26 & 0.02 & 88.89 \\
\hline 4 & 14 & 1.83 & 1.52 & 0.31 & 2 & 1.67 & 1.63 & 0.04 & 87.10 \\
\hline 5 & 24 & 1.55 & 1.38 & 0.17 & 1 & 1.85 & 1.72 & 0.13 & 23.53 \\
\hline 6 & 16 & 1.30 & 1.23 & 0.07 & 5 & 1.10 & 1.02 & 0.08 & -14.29 \\
\hline 7 & 19 & 1.53 & 1.29 & 0.24 & 1 & 2.23 & 2.15 & 0.08 & 66.67 \\
\hline 8 & 14 & 1.89 & 1.58 & 0.31 & 3 & 1.48 & 1.45 & 0.03 & 90.32 \\
\hline 9 & 8 & 1.63 & 1.43 & 0.20 & 1 & 1.55 & 1.38 & 0.17 & 15.00 \\
\hline 10 & 7 & 2.17 & 1.71 & 0.46 & 1 & 1.07 & 0.92 & 0.15 & 67.39 \\
\hline 11 & 20 & 1.42 & 1.25 & 0.17 & 2 & 1.34 & 1.16 & 0.18 & -5.88 \\
\hline 12 & 7 & 1.72 & 1.44 & 0.28 & 1 & 1.11 & 1.10 & 0.01 & 96.43 \\
\hline 13 & 16 & 1.48 & 1.21 & 0.27 & 1 & 1.07 & 0.80 & 0.27 & 0.00 \\
\hline 14 & 61 & 1.67 & 1.48 & 0.19 & 1 & 2.27 & 2.26 & 0.01 & 94.74 \\
\hline 15 & 7 & 1.52 & 1.38 & 0.14 & 1 & 1.85 & 1.80 & 0.05 & 64.29 \\
\hline Ortalama & 19.93 & 1.68 & 1.45 & 0.24 & 1.93 & 1.56 & 1.48 & 0.09 & 62.50 \\
\hline
\end{tabular}

PS; parsel sayısı, YU; ortalama yol uzunluğu, KUYU; ortalama kuş uçuşu yol uzunluğu, F; fark, FDO; farklar arası değişim oranı 
Bir parselin YU ile KUYU değerlerinin birbirine yakın olması yol ağının iyi olmasının işaretidir. Çizelge 2 incelendiğinde arazi toplulaştırma projesi uygulanmadan önce işletme KUYU ve YU arasındaki fark ortalamasının $0.24 \mathrm{~km}$ olduğu görülmektedir. Bu farkın en büyük olduğu işletme $0.46 \mathrm{~km}$ ile 10 numaralı, en düşük olduğu işletme ise $0.14 \mathrm{~km}$ ile 15 numaralı işletmedir. Parsel sayısı en fazla işletme grubunda $(20+)$ bu değer ortalama $0.18 \mathrm{~km}$ 'dir. Bu durum işletmelerde toplulaştırma öncesi parsellerin küçük, dağınık ve çok parçalı olmasına karşılık iyi bir yol ağına sahip olduğunu göstermektedir.

Arazi toplulaştırması sonrası tüm işletme grupları için YU ile KUYU farkı ortalaması $0.09 \mathrm{~km}$ olarak gerçekleşmiştir. Ortalama değerin 0.24 km'den 0.09 km'ye düşmesi; arazi toplulaştırma projesiyle yol ağının yaklaşık \%62.50 oranında iyileştiğini ifade etmektedir. Toplulaştırma sonrası YU ile KUYU arasında farkın en büyük olduğu işletme $0.27 \mathrm{~km}$ ile 13 numaralı, en düşük olduğu işletmeler ise $0.01 \mathrm{~km}$ ile 14 ve 12 numaralı işletmelerdir.
Toplulaştırma öncesi ve sonrası farklar karşılaştırıldığında yol işletim sistemindeki iyileşme genel ortalama değeri \%61.47 olmuştur. Toplulaştırma sonrası 15 işletmenin birisinde (13 numaralı işletme) fark değerlerinde değişim olmazken, ikisinde (6 ve 11 numaralı işletmeler) artış, diğerlerinde ise azalma olmuştur. Azalma oranı en fazla \%96.43 ile 12 numaralı işletmede gözlenmiştir. Toplulaştırma öncesi 63 adet, toplulaştırma sonrası 6 adet parsel ile en fazla parsele sahip 3 numaralı işletmede farklar arasında azalış \%88.89 gibi büyük bir oranda gerçekleşmiştir. Yol işletim sisteminde en iyi gelişmeyi ise $0.46 \mathrm{~km}$ farktan $0.15 \mathrm{~km}$ farka düşüş sağlayan 10 numaralı işletme göstermiştir. Bu durum 10 numaralı işletmenin toplulaştırma sonrası yoldan doğrudan yaralanan parsel sayısının artmasından kaynaklanmaktadır.

Araştırma alanında arazi toplulaştırmasının yol yeterliliğine etkileri bakımından değerlendirilmesine ilişkin veriler Çizelge 3 'te verilmiştir.

Çizelge 3. Beypınarı arazi toplulaştırması ile tarla için yol yeterliliği değişimi

\begin{tabular}{ccccc}
\hline \multirow{2}{*}{$\begin{array}{c}\text { İşletme } \\
\text { No }\end{array}$} & \multicolumn{2}{c}{ Toplulaştırma öncesi } & \multicolumn{2}{c}{ Toplulaştırma sonrası } \\
\cline { 2 - 5 } & AYU & KUYUU & AYU & KUYUU \\
\hline 1 & 11.35 & 11.13 & 6.21 & 7.19 \\
2 & 7.64 & 7.33 & 11.90 & 12.83 \\
3 & 10.23 & 10.34 & 7.98 & 9.17 \\
4 & 9.46 & 8.89 & 8.80 & 10.20 \\
5 & 3.31 & 3.34 & 3.79 & 4.61 \\
6 & 2.97 & 3.19 & 2.50 & 3.05 \\
7 & 7.54 & 7.19 & 11.59 & 13.60 \\
8 & 6.46 & 6.11 & 4.82 & 5.57 \\
9 & 5.53 & 5.49 & 4.83 & 6.14 \\
10 & 8.86 & 7.90 & 4.14 & 4.03 \\
11 & 6.73 & 6.70 & 6.58 & 4.78 \\
12 & 7.87 & 7.45 & 5.16 & 5.79 \\
13 & 3.72 & 3.44 & 2.68 & 2.27 \\
14 & 10.36 & 10.39 & 15.24 & 17.16 \\
15 & 9.06 & 9.31 & 11.19 & 13.02 \\
\hline
\end{tabular}

AYU; Alan-yol uzunluğu uygunluğu göstergesi; KUYUU; Alan-kuş uçuşu yol uzunluğu uygunluğu göstergesi

AYU değerinin bire yaklaşması işletmenin yol ağ1 sistemine göre iyi konumda olduğunu göstermektedir. AYU ve KUYUU değerlerinin birbirine yakın olması ise yol ağı uygunluğunun yeterli olduğunu işaret eder. Çizelge 3 incelendiğinde toplulaştırma öncesi AYU göstergesi 2.97 değeri ile 6 numaralı işletmede en iyi, 11.35 değeri ile 1 numaralı işletmede en kötü durumdadır. AYU ve KUYUU değerlerinin birbirine en yakın olduğu işletmeler 0,03 fark değeri ile 5 ve 14 numaralı işletmelerdir. Toplulaştırma sonrasına bakıldığında AYU değeri 6 numaralı işletme 2.50 ile en iyi, 14 numaralı işletme 15.24 değeri ile en kötü değeri almıştır. Genel olarak bakıldığında toplulaştırma öncesi parsel sayıları fazla olan parsellerde toplulaştırma sonrası AYU değeri yüksek çıkmıştır. Bunun nedeni parsel sayısının azalmasına karşılık konum itibariyle köy yerleşim yerine uzaklığının artmış olmasıdır. Toplulaştırma 
sonras1 AYU ve KUYUU değerlerinin birbirine en yakın olduğu işletme 0.11 değeri ile 10 numaralı işletme olmuştur. Arazi toplulaştırma öncesi ve sonrasında AYU ve KUYUU değerlerinin genel olarak birbirine yaklaştı̆̆ı görülmüştür. Benzer sonuçlar İlhan ve Erpul (2015), Kuzu ve ark., (2018), Değirmenci ve ark., (2018) tarafindan da rapor edilmiştir. $\mathrm{Bu}$ durum toplulaştırma projelerinin başarısı açısından beklenen bir sonuçtur.

\section{SONUC}

Arazi toplulaştırması çalışmaları, farklı geometrik şekillerde, parçalanmış, dağılmış, tarımsal üretimde sorun olabilecek derecede küçülmüş arazilerin düzgün geometrik şekillerde en uygun biçimde birleştirildiği, girdi maliyetlerinin azalmasına bağlı olarak sosyal huzurun da sağlandığı, ekonomik tarım işletmeciliği yapılmasını sağlamaktadır. Bu çalışmada Erzurum-Beypınarı arazi toplulaştırma projesi ele alınmış ve uygulama sonucunda AYU (alan-yol uzunluğu uygunluğu) ve KUYUU (alan-kuş uçuşu yol uzunluğu uygunluğu) göstergeleri kullanılarak yol yeterliliklerinin değişimi irdelenmiştir. Yoldan faydalanan parsel oranının \%68'den \%100'e ulaştığ göstergeler de yol işletim sisteminin iyileştiğini belirtmektedir. Bu sonuç, modern ve makinalı tarım tekniklerinin etkili kullanımı, yakıt giderlerinin azalması ve dolayısı ile karbondioksit salınımının azaltılması açısından arazi toplulaştırmasının önemli olduğunu işaret etmektedir. Ayrıca parsel sayısı azalmış alanı büyümüş olduğu için işgücünün etkili kullanımı da söz konusu olmaktadır.

\section{TEŞEKKÜR}

$\mathrm{Bu}$ araştırmada yardımlarını esirgemeyen Zir. Müh. İsmail Hakkı Ozan ve Zir. Müh. Öner Uçar'a teşekkür ederiz.

\section{KAYNAKLAR}

Akdeniz, M., Temizel, K. 2018. Arazi toplulaştırma projelerinde başarının değişik göstergelere göre değerlendirilmesi. Anadolu Tarım Bilimleri Derg., 33 (2): 149-161.

Akkaya Aslan, Ş.T., 2018, Arazi toplulaştırma öncesi ve sonrası arazi parçalılık değişiminin analizi: Denizli Tavas İlçesi Pınarlar Köyü örneği. Türk Tarım ve Doğa Bilimleri Derg., 5(3): 364-371.

Akkaya, S., Topak, R., Kara, M., 2017. Arazi toplulaştırmasının toplu yağmurlama şebekesi proje ve işletme maliyetlerine etkisi, Bahri Dağdaş Bitkisel Araşt. Derg., 6 (1): 1-9.
Akkaya Aslan, Ş.T., Gündoğdu, K.S., Arıcı, İ. 2007. Some metric indices for the assessment of land consolidation projects. Pakistan J. of Biological Sci., 10 (9): 1390-1397.

Arıcı, İ., Akkaya Aslan, Ş.T., 2014. Arazi Toplulaştırması Planlama ve Projelemesi. Dora Yayinları, Bursa, 237 s.

Basar, A.N., 2016. Konya Güneysınır merkez arazi toplulaştırmasının, tarımsal altyapı hizmetlerine etkisi. Selçuk Üniversitesi Fen Bilimleri Enstitüsü, Yüksek Lisans Tezi, Konya.

Boyraz, Z., Üstündağ, Ö., 2008. Kırsal alanlarda arazi toplulaştırma çalışmalarının önemi, e-Journal of New World Sciences Academy, 3 (3): 563-578.

Boztoprak, T., Demir, O., Çoruhlu, Y.E., Nişanc1, R., 2015. Arazi toplulaştırmasının tarımsal işletmelere etkilerinin araştırılması, S.Ü. Müh. Bilim ve Teknik Dergisi, 3 (3): 1-11.

Çakmak, B., Eminoğlu, G., 2013. Burdur-KemerElmacık Köyü arazi toplulaştırma etkinliğinin değerlendirilmesi. Gaziosmanpaşa Bilimsel Araştırma Derg., 5: 39-53.

Çelebi, M., 2010. Toplulaştırmanın Karaman İlinde sulama ve diğer tarımsal faaliyetlerin verimliliği üzerinde etkileri. Tarım Bilimleri Araştırma Derg., 3 (2): 1-6.

Çiçek, A., Erkan, O., 1996. Tarım Ekonomisinde Araştırma ve Örnekleme Yöntemleri. Gaziosmanpaşa Üniversitesi Ziraat Fakültesi Yay. No: 12, Ders Notları Serisi No: 6, Tokat.

Dağdelen, N., Tunalı, S.P., Gürbüz, T., Akçay, S., Yılmaz, E., 2017. Aydın Yenipazar-Hamzabali Köyünde toplulaştırma etkinliğinin araştırılması. ADÜ Ziraat Derg., 14 (1): 45-50.

Değirmenci, H., Arslan, F., Tonçer, R., Yoğun, E., 2017. Arazi toplulaştırma öncesi parsel şekilleri ve arazi parçalanmasının değerlendirilmesi: Niğde Misli Ovası Tırhan Köyü örneği. Gaziosmanpaşa Üniv. Ziraat Fak. Derg., 34 (3): 182-189.

İlhan, H., Erpul, G., 2015. Arazi toplulaştırma çalışmasında başarı analizi (fiziksel, sosyal ve ekonomik değerlendirmeler): Erzurum İli, Daphan Ovası Projesi. TMMOB Harita ve Kadastro Mühendisleri Odas1, Türkiye Harita Bilimsel Teknik Kurultayı, 25-28 Mart, 2015, Ankara.

Kirmikil, M., Aydus, D., 2018. Arazi toplulaştırma projelerinin kırsal alanlarda yakıt giderlerine ve tarımsal mekanizasyona etkisi. SDÜ Ziraat Fak. Derg. 1. Uluslararası Tarımsal Yapılar ve Sulama Kongresi Özel Sayıs1: 31-42. 
Kumbasaroğlu, H., Dağdemir, V., 2007. Erzurum merkez ilçede tarım arazilerinde parçalılık durumuna göre tarım işletmelerinin ekonomik analizi, Atatürk Üniv. Ziraat Fak. Derg., 38 (1): 49-58.

Kuşlu, Y., 2004. Kuzgun Barajı sulama alanında arazi toplulaştırma potansiyelinin belirlenmesi. Atatürk Üniversitesi Fen Bilimleri Enstitüsü, (Doktora Tezi), Erzurum, $218 \mathrm{~s}$.

Kuşlu, Y., Yağanoğlu, A.V., 2007. Kuzgun Baraj1 sulama alanında yapisal durumun belirlenmesi. Atatürk Üniv. Ziraat Fak. Derg., 38 (1): 71-81.

Kuslu, Y., Sahin, U., Kızıloglu, F.M., Okuroglu, M., 2017. Agro-ecological zones and land use planning at the Kuzgun Dam irrigation area, Atatürk Üniv. Ziraat Fak. Derg., 48 (2): 99-105.

Kuzu H., Arslan, F., Değirmenci, H., 2018. Arazi toplulaştırma projelerinde yol uzunluklarının analizi: Şanlıurfa Türkeli Köyü örneği. SDÜ Ziraat Fak. Derg., 1. Uluslararası Tarımsal Yapılar ve Sulama Kongresi Özel Sayısı: 19-25.

Mc Garigal, K., Marks, B.J., 1995. FRAGSTATS: Spatial Pattern Analysis Program for Quantifying Landscape Structure. Gen. Tech. Rep. PNWGTR-351. Portland, OR: U.S. Department of Agriculture, Forest Service, Pacific Northwest Research Station. 122 p.

MGM, 2019. https://www.mgm.gov.tr/ veridegerlendirme/il-ve-ilceler-istatistik.aspx?k =A\&m=ERZURUM (Erişim tarihi: 22 Ocak 2019)

Peker, M., Dağdelen, N., 2016. Aydın bölgesi toplulaştırma sahalarında toplulaştırma öncesi ve sonrası kültürteknik hizmetlerinin irdelenmesi, ADÜ Ziraat Fak. Derg., 13 (1): 25-33.
Platonova, D., Setkovska, L., Jankava, A., 2011. Assessment principles of land fragmentation: Baltic surveying. 11 Proceedings International Scientific Conference of Agriculture Universities of Baltic States 11th - 13th of May, Jelgava, Letonya.

Polat, H.E., Manavbaşı, İ.D., 2012. Arazi toplulaştırmasının kırsal alanda yakıt tüketimi ve karbondioksit salınımına etkisinin belirlenmesi. Tarım Bilimleri Dergisi, 18: 157-165.

Sönmezyıldız, E., Çakmak, B., 2013. Eskişehir Beyazaltın köyü arazi toplulaştırma alanında sulama performansının değerlendirilmesi. Akdeniz Üniv. Ziraat Fak. Derg., 26 (1): 33-40.

Tezcan, A., Arazi Toplulaştırma Çalışmalarında Parsel Endekslerinin Belirlenmesinde Yeni Bir Yaklaşım: Aksu Çayı Örneği, Akdeniz Üniversitesi Fen Bilimleri Enstitüsü, Doktora Tezi, Antalya, $118 \mathrm{~s}$.

Uçar, Y., Kara, M., 1997. Konya-Çumra-Küçükköy'de arazi toplulaştırmasının parsel özellikleri ve tarımsal altyapı hizmetlerine etkisi. 6. Ulusal Kültürteknik Kongresi Bildirileri 5-8 Haziran, Kirazlıyayla-Bursa, 1997, s: 51-61.

Uçar, D., Çiftçi N., Uçar, Y., 2003. Konya Çumra İlçesinin bazı köylerinde arazi toplulaştırmasının tarımsal altyapı hizmetlerine etkisi, 2. Ulusal Sulama Kongresi Bildirileri, 16-19 Ekim Kuşadası, Aydın, 2003, s: 279-290.

Uçar Y., Kara M., 2006. Arazi toplulaştırmasının su iletim ve dağıtım randımanına etkisi. KSÜ Fen ve Mühendislik Dergisi, 9 (1): 117-124. 